\title{
ReSEARCh Article \\ Effect of seed coating polymers on performance in soybean (Glycine max. L) Var. JS335
}

\author{
Jitendra Kumar S. Hilli, Rehan Malik, A.G. Vijayakumar and Ravi Hunje
}

\begin{abstract}
SUMMARY
Seed coating especially film coating, is one such technique which has gained commercial importance owning to its practical utility as an effective delivery system as seed protectant and fortifying chemicals which maintain good germinability and vigour in field as well as laboratory viz., strong seedlings grow faster than less vigorous ones, are more tolerant to adverse conditions in the seedbed and are better to resist diseases. Seeds of soybean cv. JS-335 were coated with polymer ((DISCO AGSP RED L-200), protectant (thiram and carboxin), bioagent (Mycorrhiza) and polymer untreated seeds as control. It was observed that, irrespective of the treatments, the seed quality parameters declined progressively with the increase in storage period (12 months). Under field conditions, higher vigour (2348) was noticed in seed treated with polymer (DISCO AG SP RED L-200) + Thiram + Quick roots **/ Mycorrhiza and lower vigour was seen inno polymer treatment or water + thiram. The field emergence $(\%)$ revealed that all the three polymer seed coating treatments were on par at 30 DAS $(78.07 \%, 77.19 \%$ and $77.19 \%)$ and 50 DAS $(80.99 \%, 80.11 \%$ and $79.56 \%)$ when compared to control treatment i.e., no polymer treatment or water + thiram at 30 DAS (71.68 \%) and 50 DAS (71.30\%), respectively. Among the yield attributes, significant difference was observed in seed yield/plant with treatment polymer (DISCO AG SP RED L$200)+$ Thiram + Quick roots **/ mycorrhiza registering highest $(22.20 \mathrm{~g})$ yield, while the lowest $(18.40 \mathrm{~g})$ yield was observed in polymer untreated or water + thiram.
\end{abstract}

Key Words : Soybean, Polymer coating, Mycorrhiza, Germination, Seed vigour, Protectants

How to cite this article : Hilli, Jitendra Kumar S., Malik, Rehan, Vijayakumar, A.G. and Hunje, Ravi (2021). Effect of seed coating polymers on performance in soybean (Glycine max. L) Var. JS335. Internat. J. Plant Sci., 16 (1): 52-58, DOI: 10.15740/HAS/IJPS/ 16.1/52-58, Copyright@ 2021: Hind Agri-Horticultural Society.

\section{MEMBERS OF THE RESEARCH FORUM}

Author to be contacted :

Jitendra Kumar S. Hilli, Seed Unit, University of Agricultural Sciences, Dharwad (Karnataka) India

Email : hillijs@uasd.in

Address of the Co-authors:

Rehan Malik, AICRP on BSP-STR, Seed Unit, University of Agricultural Sciences, Dharwad (Karnataka) India

A.G. Vijayakumar, Seed Unit, University of Agricultural Sciences, Dharwad (Karnataka) India

Ravi Hunje, Directorate of Post Graduate Studies, University of Agricultural Sciences, Dharwad (Karnataka) India
Article chronicle : Received : 28.08.2020; Revised : 12.11.2020; Accepted : 14.12.2020 